\title{
Importance of Double Layer Force between a Plat and a Nano-Particle in Restricting Fines Migration in Porous Media
}

\author{
Saeed Sourani' ${ }^{1}$, Mohammad Afkhami2 ${ }^{2}$, Yousef Kazemzadeh ${ }^{3 *}$, Houman Fallah ${ }^{4}$ \\ ${ }^{1}$ Department of Petroleum Engineering, Shiraz University, Shiraz, Iran \\ ${ }^{2}$ Department of Petroleum Engineering, Islamic Azad University of Marvdasht, Marvdasht, Iran \\ ${ }^{3}$ Department of Petroleum Engineering Islamic Azad University of Lamerd, Lamerd, Iran \\ ${ }^{4}$ Department of Petroleum Engineering, Islamic Azad University of Firoozabad, Firoozabad, Iran \\ Email: ${ }^{*}$ yusefkazemzade@yahoo.com
}

Received 3 May 2014; revised 20 June 2014; accepted 3 July 2014

Copyright (C) 2014 by authors and Scientific Research Publishing Inc.

This work is licensed under the Creative Commons Attribution International License (CC BY). http://creativecommons.org/licenses/by/4.0/

(c) (i) Open Access

\begin{abstract}
Fines migration is defined as separation of a Nano-sized particle by fluid flow in porous media and its migration along some distances and its entrapment in a narrow pore throat or its settlement on pore wall. Although this phenomenon happens in scales of Nano-meters, it can lead to sever irretrievable damages. This damage includes permeability reduction that causes drastic oil recovery reduction. There are several forces impacting a fine that is placed on a pore wall. Some of most important forces affecting settlement of a fine in porous media in presence of a fluid are electrical forces. Electrical forces consist of several long and short range forces. This study focuses on a long range force called Double Layer Force (DLF) that beside Van der Waals is one of most powerful electrical forces. DLF is a repulsive force that can repel a particle from pore wall and result separation of a Nano-sized solid which subsequently moves along with flowing fluid and clogs a throat. The DLF depends on the solid material (reservoir rock and fine) and fluid properties (i.e. ionic strength, $\mathrm{pH}$ ). This study investigates how each of these parameters affects DLF and introduces proper conditions for reservoir water flooding for controlling fines migration.
\end{abstract}

\section{Keywords}

Water Flooding, Reservoir Damage, Fines Migration, EOR, Double Layer Force, Inter-Particle Forces

${ }^{*}$ Corresponding author.

How to cite this paper: Sourani, S., Afkhami, M., Kazemzadeh, Y. and Fallah, H. (2014) Importance of Double Layer Force between a Plat and a Nano-Particle in Restricting Fines Migration in Porous Media. Advances in Nanoparticles, 3, 99-105. 


\section{Introduction}

Presence of Nano-particles in porous media is responsible for many hydrocarbon reservoir damages [1]. These fines are loosely attached on pore walls and during fluid flow through pores they may be separated from their own places and move along with flowing fluid. Finally these particles would be trapped in a narrower pore throat or settle on a pore wall and clog a path of fluid stream [2]. This problem happens in Nano-meter scale fines and pores, but in a hydrocarbon reservoir scale, there are plenty of these fines and pores to cause extreme permeability reduction. This permeability reduction can cause reduction in productivity or well injectivity [3].

Water flooding during secondary and tertiary recovery is one of main potentials for reservoir damage [4] [5]. Considering this fact that these damages mainly are irretrievable, water flooding inevitably should be studied before any operation for evaluating magnitude of its damages. These studies should include investigation of injection rate and chemical composition of injection agent. Although injection rate is a very important reason for fines migration, this paper studies effect of chemical composition of water, which is rarely noticed before.

Water as flooding agent creates a media that contains electrical potential adjacent to charged pore walls at very short distances from the wall surfaces [6]. Although electrical potential is very small (in scale of millivolts), but, because of low weight of Nano-particles in porous media these fines will be affected by that. The induced potential can cause a repulsive force and separate fines from pore wall and move them along some distances and cause reservoir damage. Several forces are effective in this procedure and this study focuses on one of them that is a subcategory of electrical forces; i.e. Double Layer Force. This force depends on water composition. This means that repulsive force between fines and pore wall can be altered by changing composition of the flooding agent [7].

\section{Electrical Double Layer}

Reservoir rock always bears an electrical potential in presence of reservoir fluid or any other fluid. This potential causes separation of negative and positive ions in brine solution. For example if rock surface contains positive charges (as in most of oil-wet carbonate reservoir) negative ions of brine solution will be attracted and accumulated near rock surface and form a layer of negative ions. Then, positive ions are localized after the negative layer, and this positive media are defined as a second layer. Electrical potential begins from surface, $\psi_{0}$, and decreases by proceeding into solution [8] (Figure 1).

Formation of these two layers leads to definition of double layer and double layer forces. This force can be calculated using surface potential. Surface potential itself can be calculated by a parameter named zeta potential that is an electrical potential in a certain distance from surface of solid. Zeta potential is calculable by experimental methods; however, in this study a hypothetical surface potential value (in normal ranges according to literature) is used for keeping the paper brief. Particle is considered to be made of same matter as reservoir rock; therefore, surface potential of particle will be equal to pore wall potential because they both are adjacent to same liquid.

Two assumptions are made in this study for determining DLF in porous media:

- The force between a particle and pore wall considered as a force between sphere and plate. Potential of sphere and plate are constant. This force can be calculated by Equation (2) [9]. Figure 2 shows a schematic indication of ion distribution that causes the related forces.

$$
F_{D L R}=\frac{\epsilon r_{p}}{4}\left[2 \psi_{01} \psi_{02}\left(\frac{1+\exp (-\kappa x)}{1-\exp (-\kappa x)}\right)+\left(\psi_{01}^{2}+\psi_{02}^{2}\right) \ln (1-\exp (-2 \kappa x))\right]
$$

According to this fact that sometimes fines and pore walls are of the same substance and always adjacent to same fluid:

$$
\psi_{01}=\psi_{02}=\psi_{0}
$$

Then:

$$
F_{D L R}=\frac{\epsilon r_{p} \psi_{0}^{2}}{2}\left[\left(\frac{1+\exp (-\kappa x)}{1-\exp (-\kappa x)}\right)+\ln (1-\exp (-2 \kappa x))\right]
$$

And 


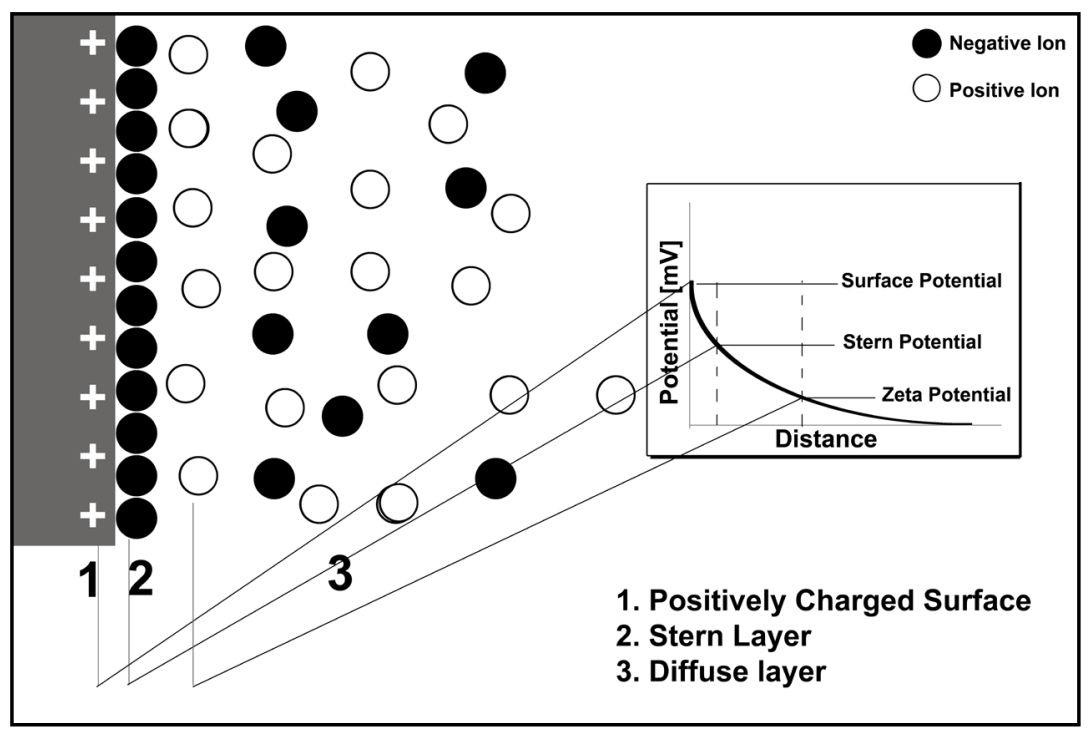

Figure 1. Electrical potential fades with increasing distance from the solid surface. Maximum potential, $\psi_{0}$, appears on solid surface and the change in electrical potential and fading rate is function of this and brine composition.

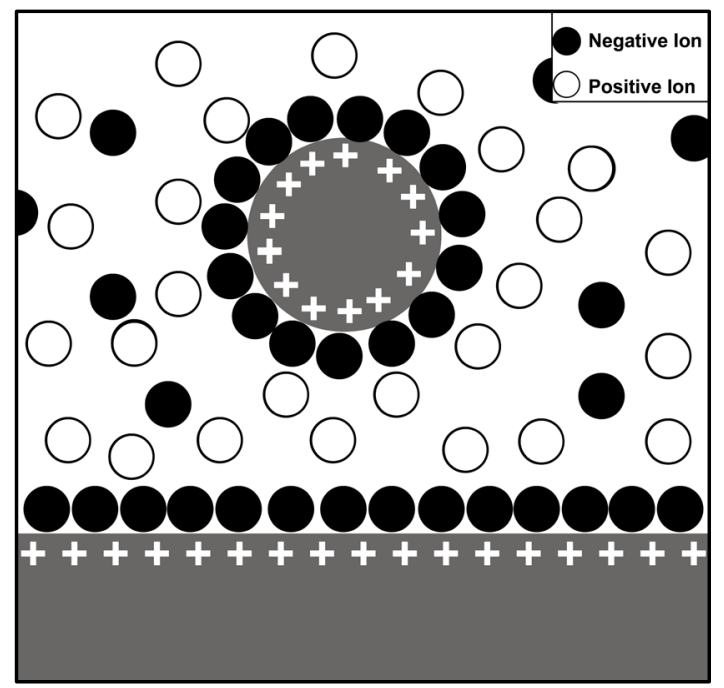

Figure 2. Ion distribution that causes the Van der Waals atraction and double layer repulsion forces between suspended particle and pore wall.

$$
\kappa=\sqrt{\frac{e^{2} \gamma}{\varepsilon k_{B} T}}, \text { and } \gamma=\sum_{i} n_{i} z_{i}^{2}
$$

where $e$ is electron potential, $\psi_{01}$ and $\psi_{02}$ refer to surface potential of plate and sphere, $\kappa$ is the reciprocal Debye length, $\gamma$ is ionic strength, $\mathrm{n}$ is ionic concentration and $z$ is valency of ion.

- All pores are wide enough that double layers induced by two walls that are placed in front of each other do not overlap; i.e. zeta potential of solution is created due to one surface charge.

According to this fact that surface charge depends on ionic strength and $\mathrm{pH}$, therefore electrical forces and properties of DL are functions of these two parameters as well. Subsequently, the possibility of releasing fines from a wall is strongly affected by ionic strength and $\mathrm{pH}$. Equations that are introduced to relate $\mathrm{pH}$ of fluid to DLF so far are not reliable and this paper only focuses on ionic strength of solution. 


\section{Composition of Conveyor Phase}

As can be seen from Equations (1) and (2), DLF is a function of ionic strength and composition because of its dependency on Debye length, $\kappa$, and permittivity, $\epsilon$. In this study, calculations are made based on the data summarized in Table 1.

\subsection{Changes of Debye Length with Ionic Strength}

Debye length is a function of ion concentrations and their valences Figure 3 shows impact of valance and concentration on Debye length caused a charged solid. As can be seen, increasing valence of ions leads to increasing Debye length; i.e. decreasing diffuse layer distance from surface of solid. This implies that density of ions close to the solid surface increases when ionic strength increases.

Reservoir temperature and water injected in reservoir (or any flowing fluid in pores) may have different temperatures. Figure 4 shows that increasing temperature decreases Debye length and the changes cause via temperature are more effective for higher ionic strengths.

According to Figure 3 and Figure 4 the changes in salinity, ion type, and temperature affects Debye length which this directly leads to changes in DLF. This effect will be studied in following sections.

Table 1. Values of the parameters used in this study.

\begin{tabular}{cc}
\hline Parameter & Value \\
\hline Surface potential, $\psi_{0}[\mathrm{~V}]$ & Variable \\
Boltzmann Constant, $k_{B}[\mathrm{j} / \mathrm{k}]$ & $1.38 \times 10^{-23}$ \\
Permittivity of Media, $\varepsilon$ & 80 \\
Electron Charge, $e[\mathrm{C}]$ & $1.602 \times 10^{-19}$ \\
Temperature, $T[\mathrm{k}]$ & Variable \\
Particle Radius, $r_{p}[\mathrm{~m}]$ & $10^{-8}(10 \mathrm{~nm})$ \\
Concentration [molar] & Variable \\
Ionic Valence & $1,2,3$ \\
Distance of Particle and Wall, $x[\mathrm{~m}]$ & $10^{-10}(1 \AA)$ \\
\hline
\end{tabular}

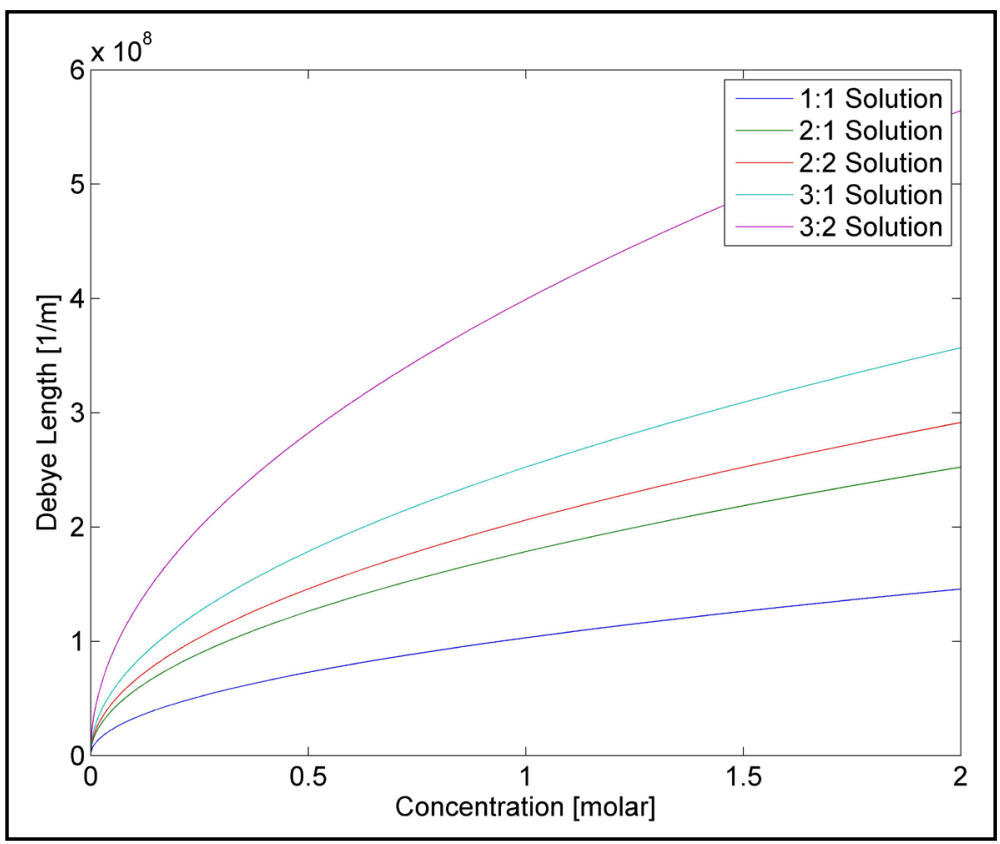

Figure 3. Debye length changes with concentration and different salts dissolved in water. Increasing ionic strength increases Debye length. It means that ions are more concentrated around solid surface. 


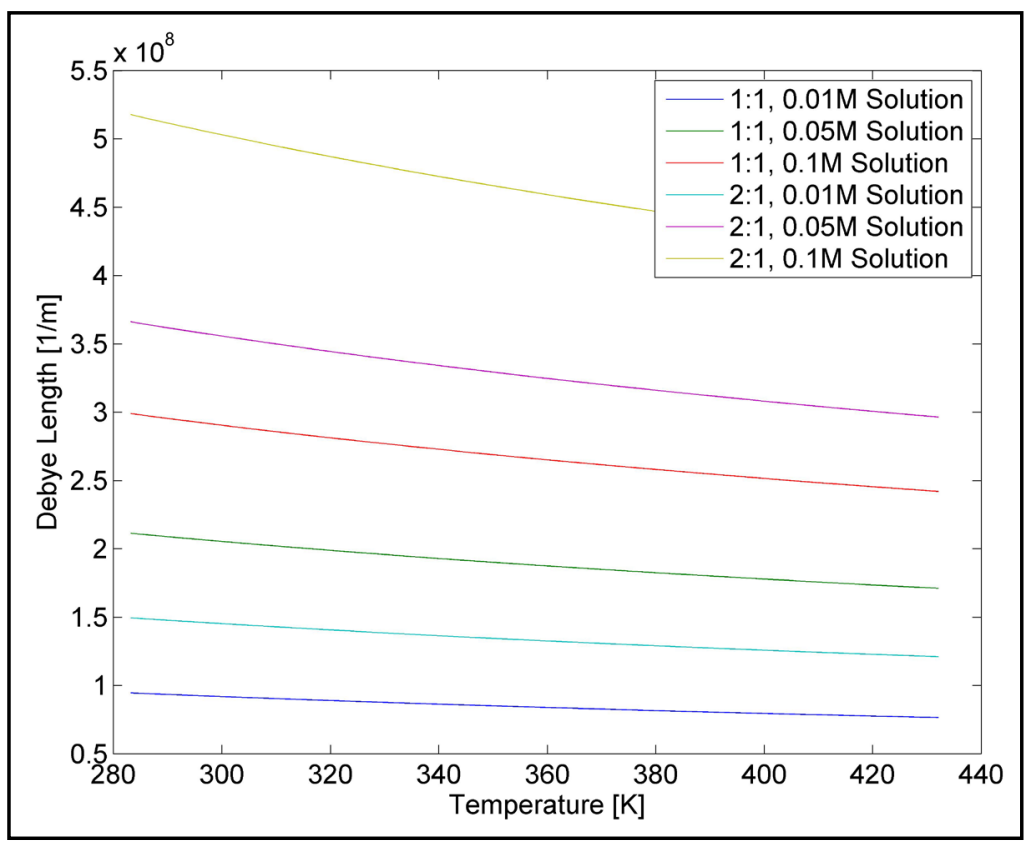

Figure 4. Debye length changes with Temperature. In higher temperature Debye length decreases. Temperature changes are more effective in higher ionic strengths.

\subsection{Changes of DLF with Ionic Strength}

In accordance with Figure 3 that shows increasing ionic strength increases Debye length, Figure 5 explains that by increasing salinity DLF between the particle and plate decreases. Though increasing ionic strength decreases DLF, at very low concentrations the forces of different valences shows different trend compared to the general trend (that the higher ionic strengths cause higher DL repulsive). Another important point is that according to Equation (2) at lower concentrations the DLF acts as an attractive force! These shows that either this equation shouldn't be used for such low concentrations or this force can't always be called as "repulsive”.

\subsection{Changes of DLF with Increasing Distance from Surface}

Effect of distance between particle and plate on DLF is shown in Figure 5. This factor impacts entrapping of a moving particle to adsorb on pore wall and also releasing a particle according to its position on the wall.

DLF tends to zero when $x \rightarrow \infty$. Also DLF tends to $\infty$ when $x \rightarrow 0$. This shows that no particle can stand exactly on a surface with zero distance.

\subsection{Changes of DLF with Temperature}

Temperature effect is shown in Figure 6. As in figure, temperature affects DLF, through this effect is very small. By comparison between these six figures it is understood that temperature has more effect when brine has higher salinity.

Also considering other parameters affecting DLF, the effect of temperature is negligible. But in more sensitive calculations it may be important to consider temperature in more concentrated solution. This leads to this fact that when there is reservoir brine re-injection or sea water injection, it may be important to notice reservoir temperature beside salinity of injection fluid for avoiding drastic damages due to fines migration.

\section{Fines Migration}

In this section of paper it is tried to explain fines migration phenomena, briefly. This phenomenon is one of the most important parameters in reservoir maintenance for avoiding irreversible reservoir damages and early production reduction. 


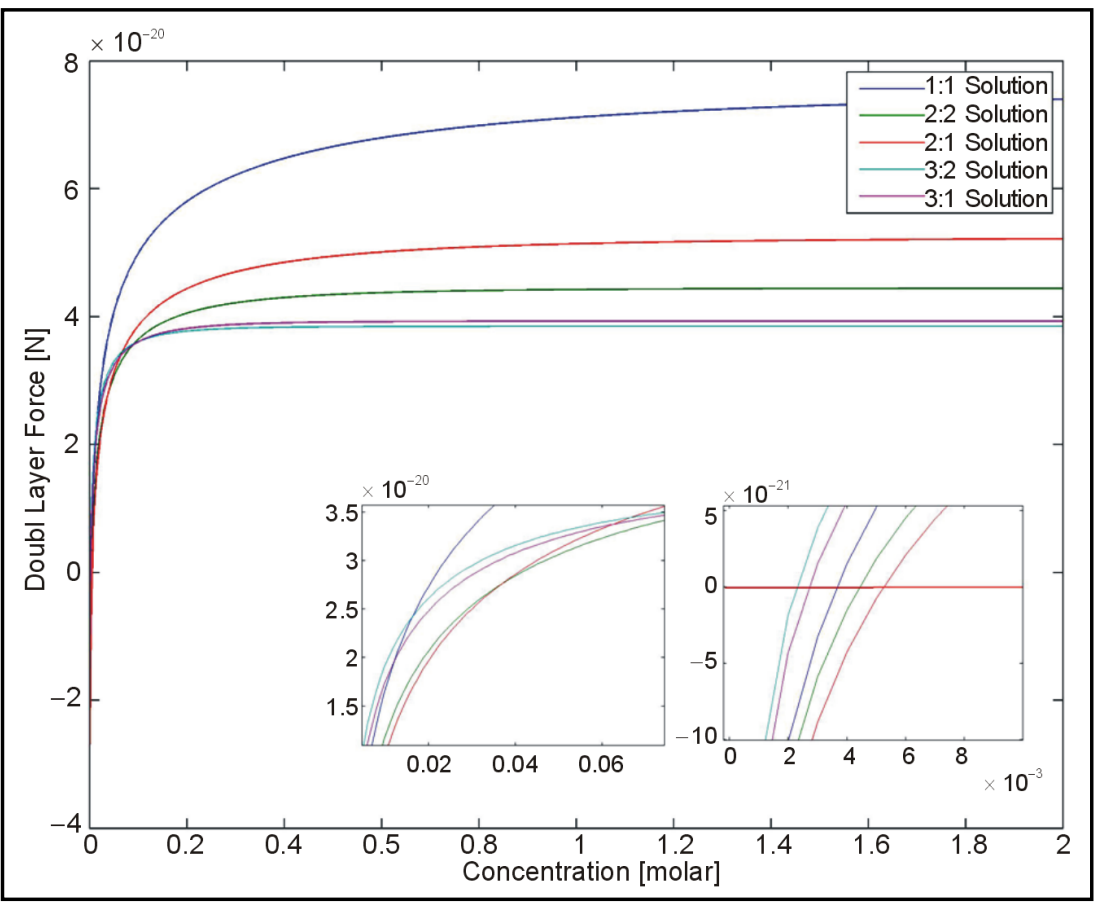

Figure 5. Effect of ionic strength on double layer forces; at very low concentrations the behavior is in contrary with the general trend.
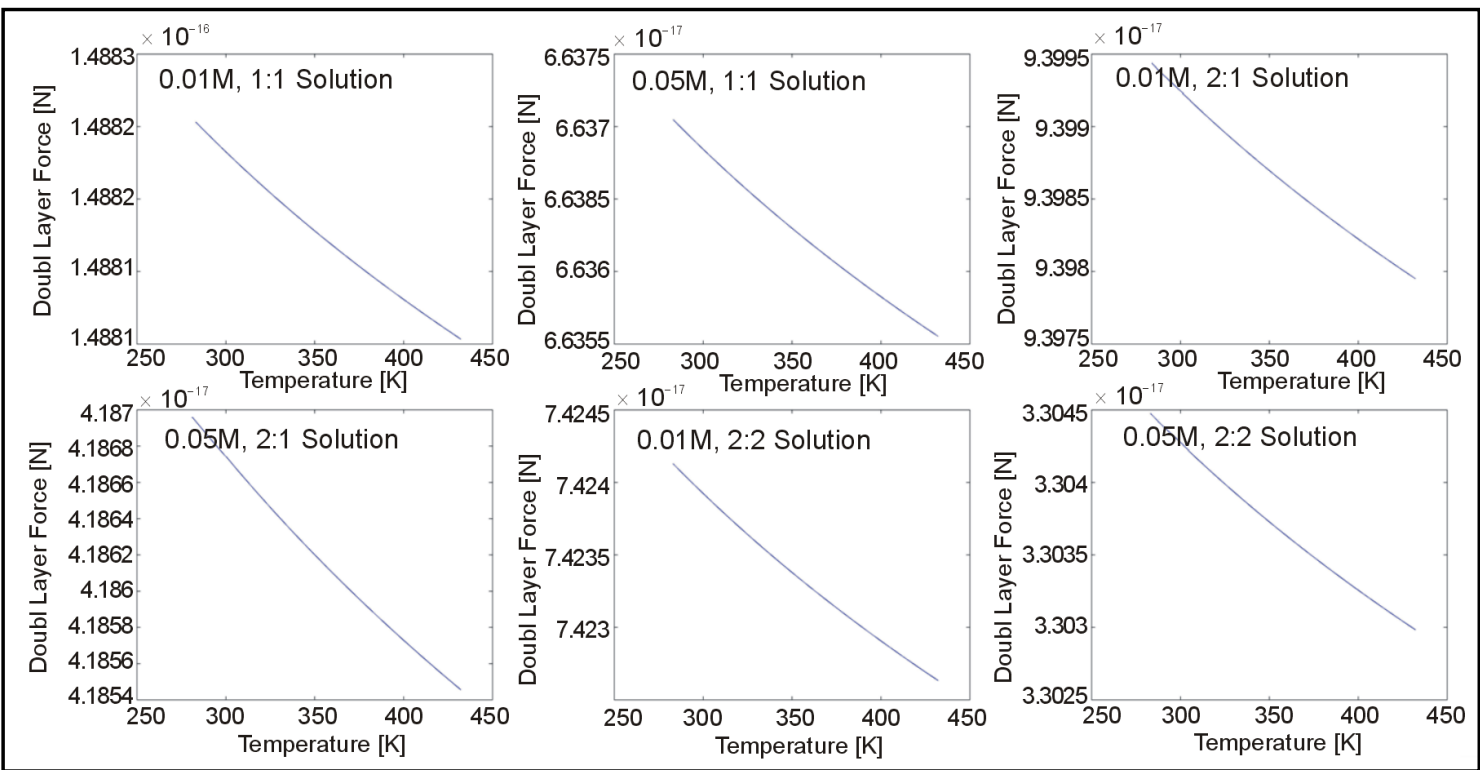

Figure 6. DLF changes temperature. It is obvious that temperature has very slight effect on DLF and its effects may be neglected in related calculations. Temperature also affects solutions with higher ionic strength. So when sea water or reservoir brine is injected into reservoir it may be important to consider reservoir Temperature to avoid more fines migration and damages.

There are five forces that affect movement of a fine in porous media; DLF, Van der Waals, drag, lift, gravity. Effect of these forces has been investigated separately by the author. DLF is one major force between these five forces. It can be easily and effectively controlled by altering salinity of injection fluid. This paper showed that how salinity can affect DLF in different thermal conditions of reservoir. To avoid fines migration we should try to decrease DLF force as much as possible. With decreasing this repellant force, a fine that is settled on a pore 
wall will stay in its place and won’t move, and therefore doesn't cause any damages.

\section{Conclusions}

Inter-molecular forces have important roles in determining behaviors of material in different fields. Mathematical calculations in this work explained circumstances of fine separation from a solid surface, which is defined as fine migration in porous media. This phenomenon causes serious damages in hydrocarbon reservoirs because of clogging pores and permeability reduction.

There are several parameters affecting migration of fines. Some of these parameters are reservoir formation characteristics and some of them are injected agent properties. Some of these affecting parameters such as ionic strength (ion valences and their concentrations), velocity of injected fluid, and particle and pore wall spacing and their influences on discussed phenomenon were studied in this work. Effect of each parameter on the electrical properties of media and the resultant forces that may cause releasing of fines from a wall is summarized as follow.

- Debye length increases with ionic strength of solution that means the ions will be concentrated around the charged solid and decrease the distance between diffuse layer and solid face.

- Increasing Debye length reduces the DL repulsion; it means that in higher ionic strengths, repulsion is lower. This implies that in unconsolidated reservoir with high concentration of fines susceptible to migrate, high salinity water should be injected to avoid reservoir damages.

- According to this fact that Debye length is more in high salinity water, then, ions are concentrated near surface so DLF is higher for high salinity brines in this area.

- According to Figure 4, there is several points about change of DLF with salinity:

1) Although increasing salinity leads to reduction of DLF, in some areas DLF is more for higher concentrations.

2) There is some disturbance in very low concentration in the same distance. This disturbance occurs in higher salinities when the distance between particle and pore wall is more.

3) In very thin brines (almost distilled water) DLF acts as an attractive force which means whether the definition of DLF as a repulsive force is not always true or the formula given for calculating DLF is not always valid.

- Reservoir temperature can be effective and determinative during reservoir water flooding in critical situations. Temperature factor is more important in higher salinity water agents.

- Although very low salinity water injection is not suggested in this paper because of its effect on separation of fines, but very concentrated brines also may cause increasing fines migration in low temperature reservoirs.

\section{References}

[1] Khilar, C.K. and Fogler, H.S. (1999) Migrations of Fines in Porous Media. Springer, Berlin.

[2] Bedrikovetsky, P., Furtado, C.A., de Souza, A.L.S. and Siqueira, F.D. (2007) Internal Erosion in Rocks during Produced and Seawater Injection. SPE Europec/EAGE Annual Conference and Exhibition, London, 11-14 June 2007, SPE 107513.

[3] Moghadasi, J., Jamialahmadi, M., Müller-Steinhagen, H., Sharif, A., Izadpanah, M.R., Motaei, E. and Barati, R. (2002) Formation Damage in Iranian Oil Fields. SPE 73781.

[4] Kwan, M.Y.M., Cullen, M.P, Jamieson, P.R. and Fortier, R.A. (1988) A Study of Fines Migration Related Permeability Damage in Extracted Cold Lake Heavy Oil Cores. 39th Annual Technical Meeting of the Petroleum Society of CIM, Calgary, June 12-16 1988.

[5] Valdya, R.N. and Fogler, H.S. (1992) Fines Migration and Formation Damage: Influence of pH and Ion Exchange. SPE Production Engineering, 7, 325-330. http://dx.doi.org/10.2118/19413-PA

[6] Adamson, A.W. and Gast, A.P. (1997) Physical Chemistry of Surfaces. Wiley-Interscience Publication, New York, Chapter 5, 170.

[7] Sourani, S., Riazi, M., Kazemzadeh, Y. and Fallah, H. A New Approach for Evaluating Migration of Nano Particles in Porous Media. Journal of Dispersion Science and Technology. http://dx.doi.org/10.1080/01932691.2014.921859

[8] Ross, S. and Morrison, I.D. (1988) Colloidal Systems and Interfaces. John-Wiley Publication, New York.

[9] Takashi, S. (2009) Water Imbibition, Electrical Surface Forces, and Wettability of Low Permeability Fractured Porous Media. Ph.D. Thesis, Stanford University, Stanford. 
Scientific Research Publishing (SCIRP) is one of the largest Open Access journal publishers. It is currently publishing more than 200 open access, online, peer-reviewed journals covering a wide range of academic disciplines. SCIRP serves the worldwide academic communities and contributes to the progress and application of science with its publication.

Other selected journals from SCIRP are listed as below. Submit your manuscript to us via either submit@scirp.org or Online Submission Portal.
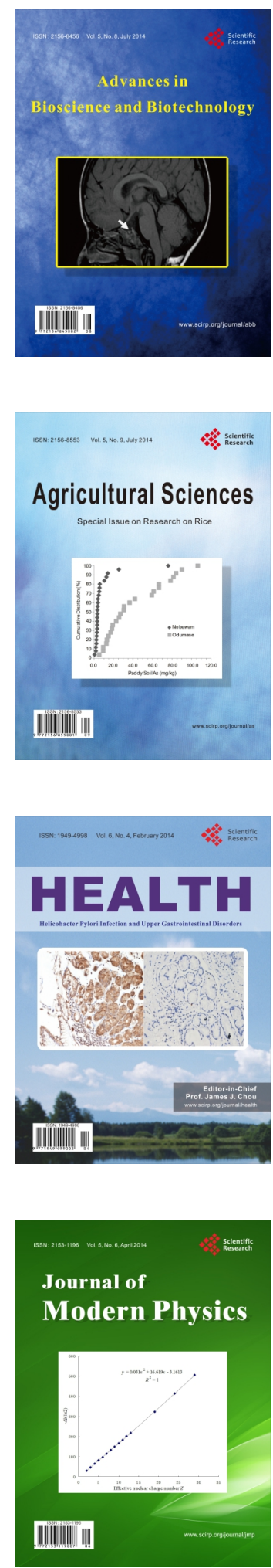
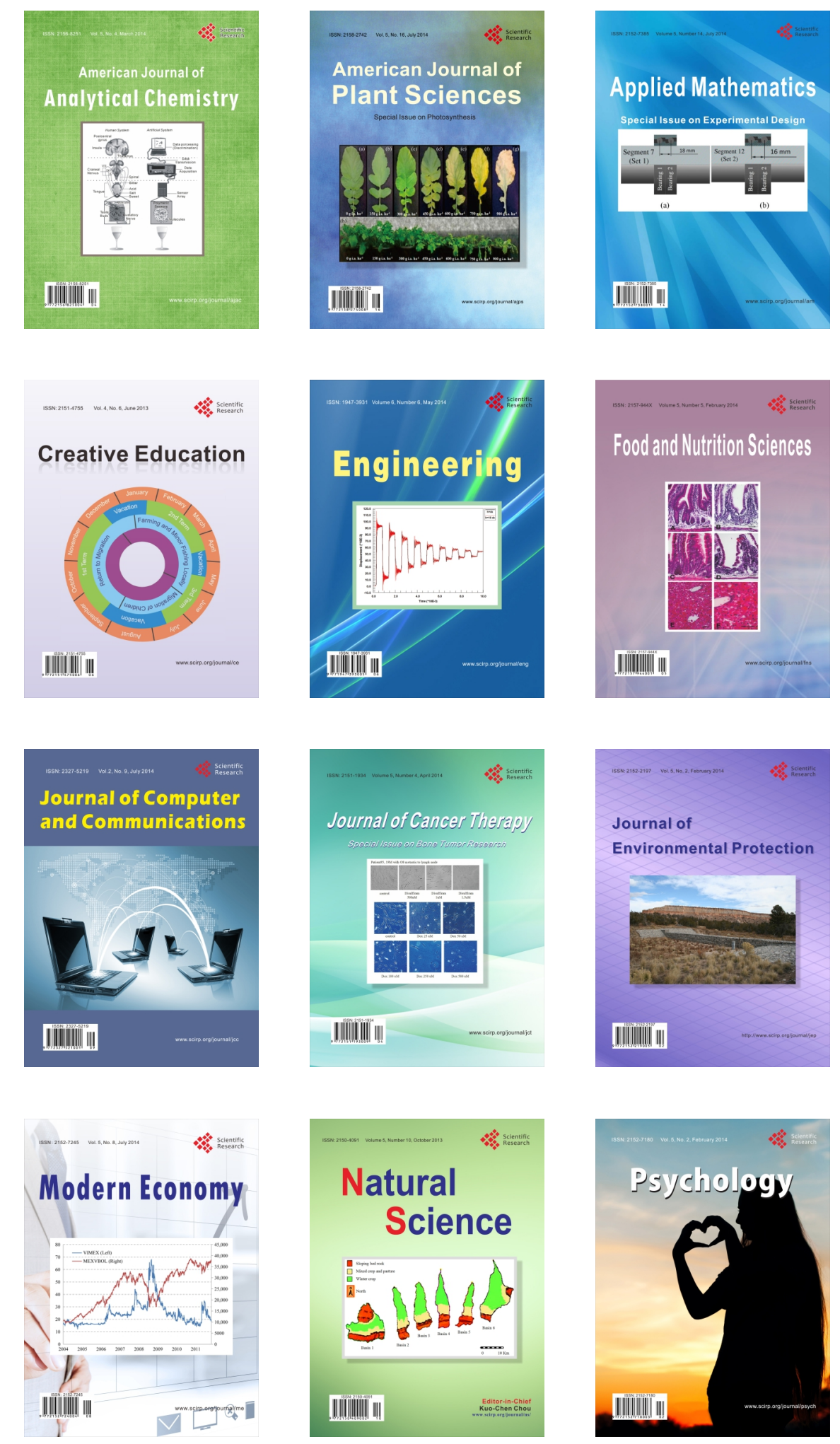